\title{
THERMAL-STRUCTURAL DESIGN OF ACTIVELY-COOLED PANELS REINFORCED BY LIGHT-WEIGHT TRUSS CORES
}

\author{
Hongwei Song \\ Key Laboratory for Mechanics in Fluid Solid \\ Coupling Systems, Institute of Mechanics, \\ Chinese Academy of Science \\ Beijing, China
}

\author{
Chenguang Huang \\ Key Laboratory for Mechanics in Fluid Solid \\ Coupling Systems, Institute of Mechanics, \\ Chinese Academy of Science \\ Beijing, China
}

\author{
Mingjun Li \\ Key Laboratory for Mechanics in Fluid Solid \\ Coupling Systems, Institute of Mechanics, \\ Chinese Academy of Science \\ Beijing, China \\ Xi Wang \\ Key Laboratory for Mechanics in Fluid Solid \\ Coupling Systems, Institute of Mechanics, \\ Chinese Academy of Science \\ Beijing, China
}

\begin{abstract}
This paper focuses on thermal-structural analysis and lightweight design of actively-cooled panels reinforced by low density lattice-framed material (LFM) truss cores. Numerical models for actively-cooled panels are built up with parametric codes to perform the coupled thermal-structural analysis, considering the internal thermal environment of convective heat transfer in the combustor and convective heat transfer in the cooling channel, and internal pressures from the combustion gas and the coolant. A preliminary comparison of the LFM truss reinforced actively-cooled panel and the non-reinforced panel demonstrates that the thermal-structural behavior is significantly improved. Then, an optimization procedure is carried out to find the lightest design while satisfying thermal deformation and plastic strain constraints, with thicknesses of face sheets and topology parameters of LFM truss as design variables. The optimization result demonstrates that, compared with the nonreinforced actively-cooled panels, weight reduction for the panel reinforced by LFM truss may reach $19.6 \%$. We have also fabricated this type of actively-cooled panel in the laboratory level, and the specimen shows good mechanical behaviors.
\end{abstract}

\section{INTRODUCTION}

Light weight and thermal protection requirement calls for new challenge to the structural design of hypersonic propulsion system. To withstand severe aerodynamic heat loads and supersonic combustion in a scramjet combustor, regenerative cooling using onboard hydrocarbon fuel has been proposed and demonstrated to be a reliable thermal management solution [13]. A typical actively-cooled panel for the combustor is illustrated in Fig.1. The key problem for such a panel is how to perform light-weight design while retaining good performances in thermal protection and load bearing. Since elevated temperatures degrade a material's ability to withstand loads and reduce a structure's stiffness, light-weight design measures such as reduction of panel thickness may significantly increase deformation, decrease buckling loads, and alter flutter behavior.

Recently, sandwich panels with light-weight truss cores receive extensive attention due to the significant advantages in multifunction, such as light weight, high specific strength and stiffness, thermal insulation, shock resistance, and vibration suppression. The mechanical benefits of sandwich structures with various topologies have been well documented in recent literatures [4-6]. Metallic sandwich structures with periodic truss and prismatic cores have been fabricated and applied in lightweight and compact heat sinks, and demonstrated the capability of simultaneous load bearing and actively-cooled $[7,8]$. Structural optimization of sandwich panels subject to various loadings and various applications has been addressed $[5,9,10]$, however, little work has been done on the complex sandwich structure that subject to complex thermal-mechanical loads, such as the case of a lattice-framed material (LFM) truss reinforced actively-cooled combustor panel during service.

In this paper, we proposed a type of light-weight latticeframed material (LFM) truss reinforced actively-cooled panel, which combines merits of traditional cooling channels in heat 
transfer and merits of sandwich structures in bearing mechanical load and light-weight design. Parametric numerical models are built up to perform the thermal-structural analysis when a combustor is working at flying Mach 6. Based on the subproblem approximation method, the optimization of LFM truss reinforced actively-cooled panel is implemented. Fabrication of this type of panel is also achieved in the laboratory level.

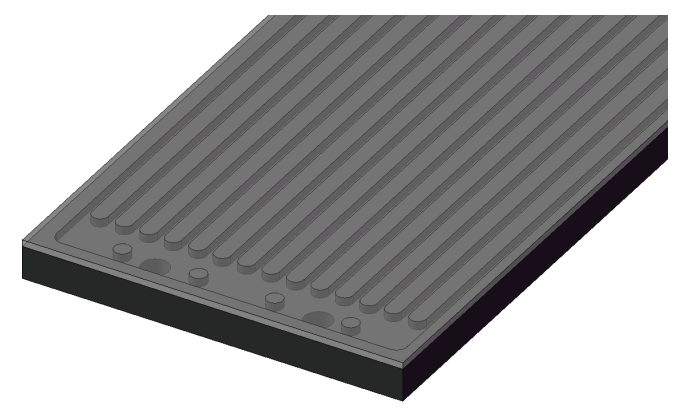

Figure 1: A typical actively-cooled panel

\section{MODEL DESCRIPTION}

The physical model for the LFM truss reinforced activelycooled panel and non-reinforced panel is illustrated in Fig.2. The length of panels is $800 \mathrm{~mm}$, and the width is $70 \mathrm{~mm}$ (in the half model, the width is $35 \mathrm{~mm}$ ). The cross section dimension of rectangular ducts is $1.5 \mathrm{~mm} \times 1.5 \mathrm{~mm}$, and spacing between ducts is $3 \mathrm{~mm}$.

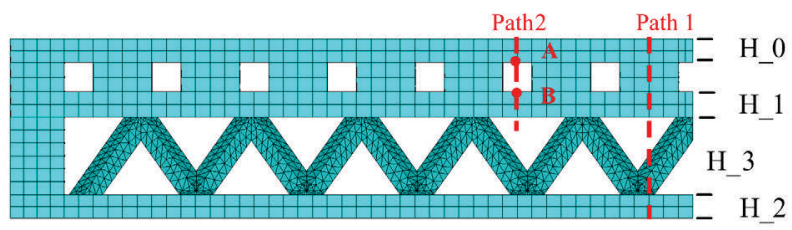

(a) LFM reinforced actively-cooled panel

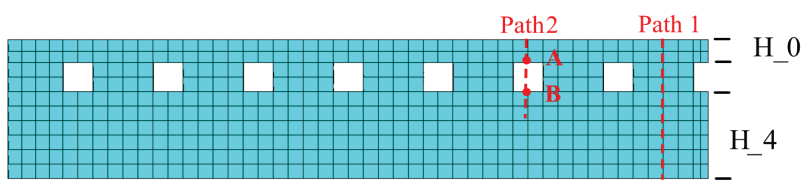

(b) Non-reinforced actively-cooled panel

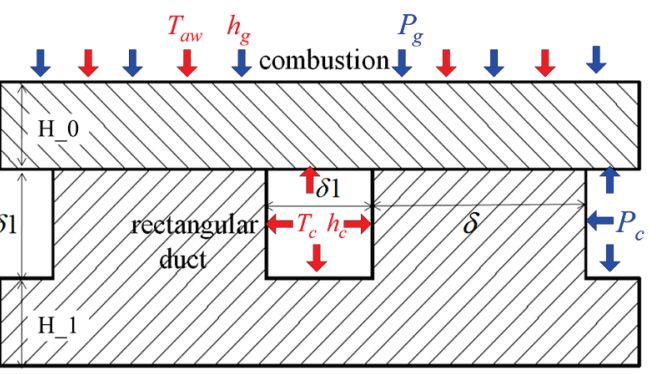

(c) Illustration of thermal-mechanical loading

Figure 2: Schematic of physical model
Hydrocarbon fuel works as coolant and flows through the rectangular ducts. Thermal loadings along the combustion side and coolant-passage channels, and internal pressures from the combustion gas and high-speed coolant is considered in the model. The convective coefficient and adiabatic temperature along the combustion side, and the convective coefficient and coolant temperature along the cooling channels, while the scramjet combustor working at Mach 6, is illustrated in Annex A [11].

\section{THERMAL-STRUCTURAL ANALYSIS}

The design of thermal structures requires to determine temperatures, displacements, stresses, and strains throughout the structures. A structural heat transfer analysis is needed to determine maximum operating temperatures that guide material selection, and temperature distributions are also needed to compute the thermal stress and thermal deformation.

The transient temperature field can be calculated according to the classical Fourier's heat conduction

$$
\rho c \frac{\partial T}{\partial t}-\frac{\partial}{\partial x_{i}}\left(k_{i j} \frac{\partial T}{\partial x_{j}}\right)=0
$$

where $\rho$ and $c$ are the material's density and specific heat, respectively, $k_{i j}$ are components of a thermal conductivity tensor.

Convective heat transfer boundary conditions are adopted in combustion side and cooling channels

$$
\begin{aligned}
& -\left.k \frac{\partial T}{\partial n}\right|_{\text {comb }}=h_{g}\left(T_{a w}-T_{w}\right) \\
& -\left.k \frac{\partial T}{\partial n}\right|_{\text {cool }}=h_{c}\left(T_{w}-T_{c}\right)
\end{aligned}
$$

where $h_{g}$ and $T_{a w}$ are the convective coefficient and adiabatic temperature along the combustion side, respectively, and $h_{c}$ and $T_{c}$ are the convective coefficient and coolant temperature along the cooling channels respectively, see Fig.2(c) and Annex A for details.

For a homogeneous, isotropic material this constitutive relation may be written as

$$
\sigma_{i j}=\lambda \delta_{i j} \varepsilon_{k k}+2 G \varepsilon_{i j}-(3 \lambda+2 G) \delta_{i j} \alpha\left(T-T_{0}\right)
$$

where $\sigma_{i j}$ and $\varepsilon_{i j}$ are components of stress and strain tensors, $\delta_{i j}$ is the Kronecker delta, $\lambda$ and $G$ are the Lame' constants; $\alpha$ is the coefficient of thermal expansion, and $T_{0}$ is the reference temperature for zero thermal stress.

In the present analysis, 304 stainless steel is adopted as the panel material. For small temperature changes the material properties are constant, however, in the present case the material experiences large temperature changes. Therefore, a bilinear elastic-plastic model for the 304 stainless steel is applied, and the nonlinear variation of thermal parameters and mechanical properties with temperature is considered. 
The coupled physics problem is solved in a sequential way to study the $3 \mathrm{D}$ thermal-structural behavior of the activelycooled panels reinforced by LFM truss. A steady-state thermal analysis is implemented to determine the temperature field. Convective heat transfer boundary conditions at Mach 6 [11] are applied both to the combustor face and the internal channel surfaces. In the structural analysis stage, the external pressure $\left(P_{g}=5 M P a\right)$ from the combustion gases, internal pressure $\left(P_{c}=1.5 \mathrm{MPa}\right)$ from the coolant are applied in the model.

\section{COMPARISON OF REINFORCED PANELS WITH NON- REINFORCED PANELS}

Compared with the non-reinforced panel, it is obvious that the truss reinforced sandwich panel possesses higher specific stiffness and higher specific strength. The truss core made of low relative density LFM can significantly augment the distance between the top face sheet and the bottom face sheet of the panel, with little weight cost, while the stiffness of the panel is proportional to the cube of panel height. Meanwhile, the reinforcement truss can hardly alter the temperature field, since the low density LFM truss introduces little heat sink and convective area, it has will not affect the thermal protection behavior of the actively-cooled panel.

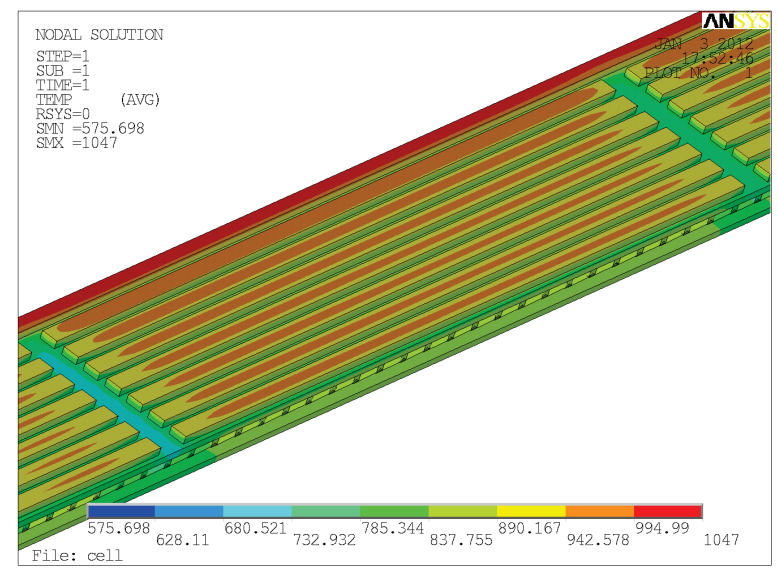

(a) Temperature field of actively-cooled channels

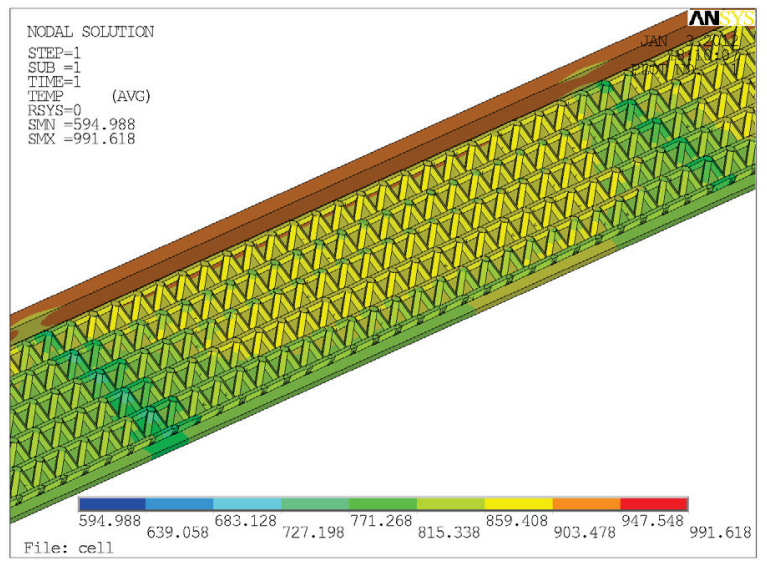

(b) Temperature field of reinforced LFM truss

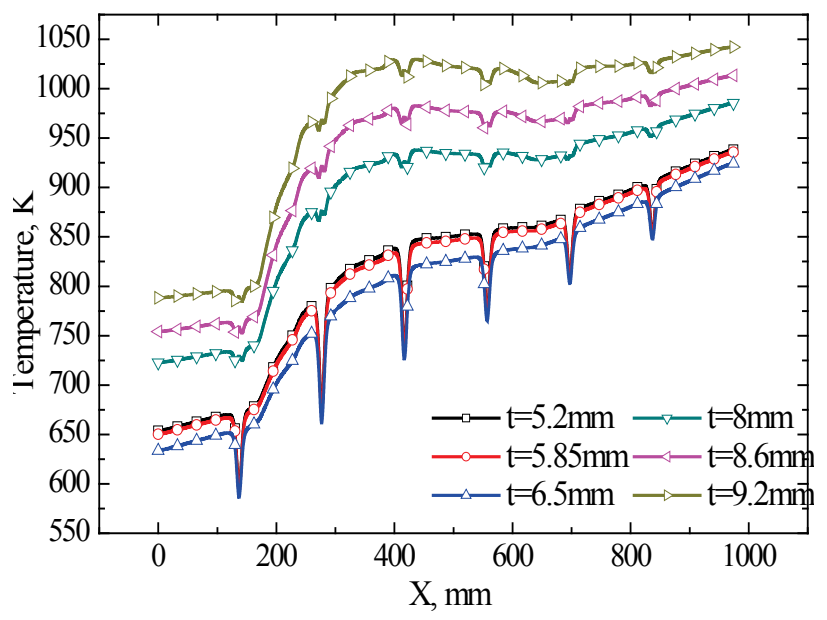

(c) LFM truss reinforced panel, along path2

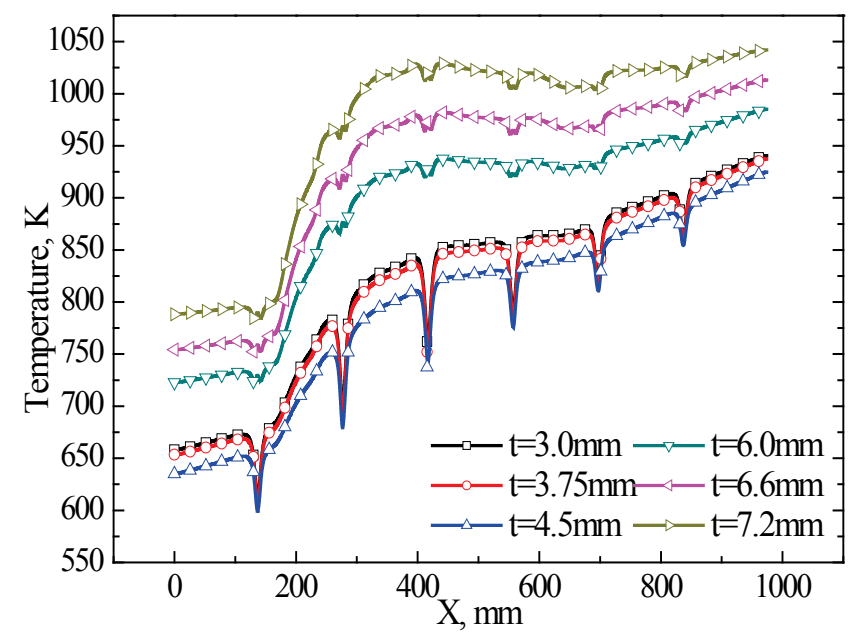

(d) non-reinforced panel, along path2

Figure. 3: Comparison of temperature field

Numerical results and thermal response and structural response are shown in Fig.3 and Fig.4.

Fig. 3 gives the direct comparison of temperature fields for a LFM truss reinforced panel and non-reinforced panel. It should be noted that according to numerical model illustrated in Fig. 2, the truss reinforced panel is about $17 \%$ weight saving compared to the non-reinforced one. Fig.3 (b) is the comparison of temperature distribution along the panel depth and length, the path is illustrated in Fig.2. Little temperature difference is found between the two types of panels.

Fig. 5 gives comparison of von Mises stress field. There is slight stress concentration at the interface of truss and top face sheet. The overall stress level is quite comparable.

The next step is finding the optimal design for the LFM reinforced actively-cooled panel. 

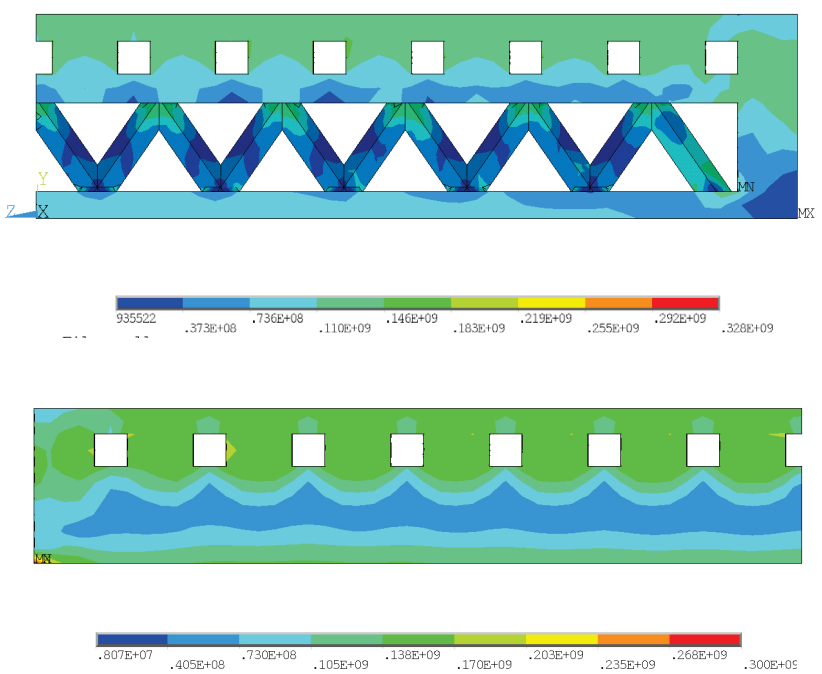

Figure. 4: Comparison of von Mises stress field

\section{OPTIMIZATION PROCEDURE}

Two types of optimization methods are used in ANSYS program to accommodate a wide range of optimization problems. One is subproblem approximation method that can be efficiently applied to most engineering problems. The other is first order method which is based on design sensitivities and is more suitable for problems requiring high accuracy.

The subproblem method is adopted for its practicability and reliability. This method requires only the values of the dependent variables (objective function and state variables). The dependent variables are first replaced with approximations by means of least squares fitting, and the constrained minimization problem is converted to an unconstrained problem using penalty functions. Minimization is then performed every iteration on the approximated, penalized function until convergence is achieved or termination is indicated. Since the method relies on approximation of the objective function and each state variable, a certain amount of data in the form of design sets is needed. This preliminary data can be directly generated by the user using any of the other optimization tools or methods. If not defined, the method itself will generate design sets at random.

$$
H=a_{0}+\sum_{n=1}^{N} a_{n} X_{n}+\sum_{n=1}^{N} b_{n} X_{n}^{2}+\sum_{m=1}^{N-1} \sum_{n=m+1}^{N} c_{m n} X_{m} X_{n}
$$

where $H$ is the approximation of dependent variables, $X$ is independent variable, $N$ is the number of independent variables.

Convergence is assumed when one of the following conditions is satisfied.

$$
\begin{array}{ll}
\left|f^{j}-f^{j-1}\right| \leq \tau & \\
\left|f^{j}-f^{b}\right| \leq \tau & \\
\left|x_{i}^{j}-x_{i}^{j-1}\right| \leq \rho_{i} & (i=1,2, \cdots, n) \\
\left|x_{i}^{j}-x_{i}^{b}\right| \leq \rho_{i} & (i=1,2, \cdots, n)
\end{array}
$$

where $f^{j} f^{j-1} f^{b}$ are the present objective function, previous objective function, and best objective function respectively, $x^{j}, x^{j-1}, x^{b}$ are the present design set, previous design set, and best design set, $\tau, \rho$ are objective function and design variable tolerances.

The flowchart of optimization process is illustrated in Fig.5. For the optimization in ANSYS, the program performs a series of analysis-evaluation-modification cycles. That is, an analysis of the initial design is performed; the results are evaluated against specified criteria, and the design is modified as necessary. The process is repeated until all specified criteria are met.

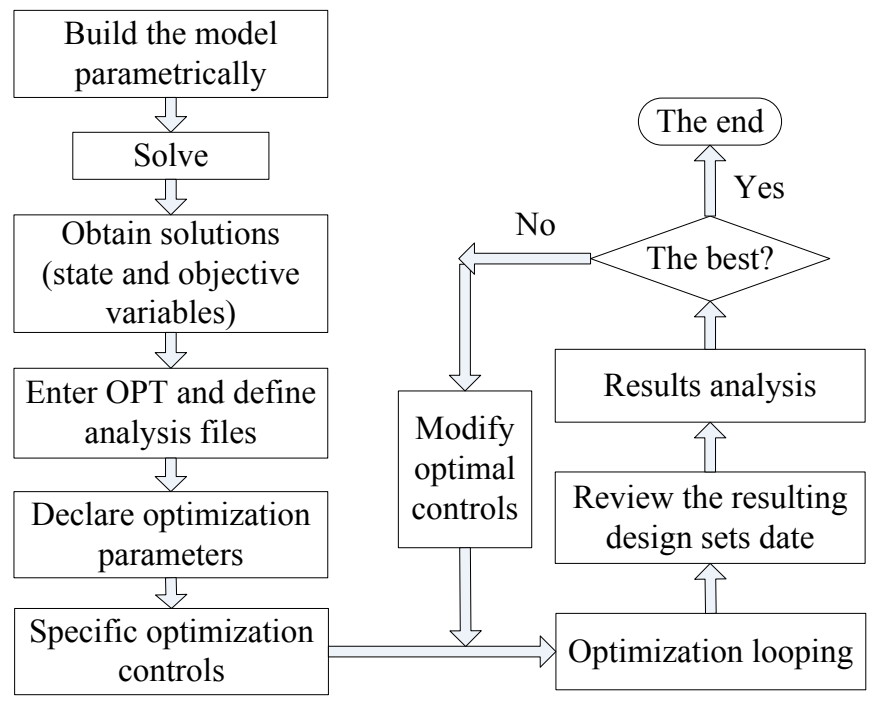

Figure 5: Optimization process

Declaration of the optimization parameters is a very important step. The design variables (DV), state variables (SV) and objective function (OBJ) in the present optimization problems are considered as the following:

Design Variables (DV):

Four-parameter optimization is performed for activelycooled panel reinforced by pyramidal truss:

- - Thickness of face-sheet at combustion side, $\mathrm{H}_{-} 0$;

- - Thickness of top face sheet for LFM, H_1;

- - Thickness of bottom face sheet for LFM, H_2;

- - Truss width of the core member, $t$.

- - To keep the optimization tractable, some parameters are fixed, e.g., $\omega=45^{\circ}, H_{-} 3=7.07 \mathrm{~mm}$ for the pyramidal truss configuration. 


\section{State Variables (SV):}

Typically failure criteria are used as design constraints. In the present case, the optimal design is limited by vertical displacement $\left(u_{y} \leq 1 \mathrm{~mm}\right)$ and von Mises plastic strain $\left(s_{p} \leq 0.02\right)$ of the actively-cooled panels.

\section{Objective Function (OBJ):}

The objective of the optimization is to find the geometric parameters that minimize weight. Since the same material is used in the optimization, volume of the structure is used as the objective function instead of weight.

Variables, ranges and tolerances adopted in the optimization process can be found in Table 1 .

Table 1: Variables, ranges and tolerances

\begin{tabular}{lllll}
\hline Variable & Item & Parameter & Range & Tolerance \\
\hline $\begin{array}{l}\text { Design } \\
\text { Variables } \\
\text { (DV) }\end{array}$ & $\begin{array}{l}\text { face sheet } \\
\text { thickness, } \\
\text { combustor side }\end{array}$ & H_0 & $1.0 \sim 4.0 \mathrm{~mm}$ & $0.03 \mathrm{~mm}$ \\
\cline { 2 - 5 } & $\begin{array}{l}\text { Top face sheet } \\
\text { for LFM }\end{array}$ & H_1 & $1.0 \sim 4.0 \mathrm{~mm}$ & $0.03 \mathrm{~mm}$ \\
\cline { 2 - 5 } & $\begin{array}{l}\text { Bottom face } \\
\text { sheet for LFM }\end{array}$ & H_2 & $1.0 \sim 4.0 \mathrm{~mm}$ & $0.03 \mathrm{~mm}$ \\
\cline { 2 - 5 } & Truss width & PY_K & $0.6 \sim 3.0 \mathrm{~mm}$ & $0.02 \mathrm{~mm}$ \\
\hline $\begin{array}{l}\text { State } \\
\text { Variables } \\
(\text { SV })\end{array}$ & $\begin{array}{l}\text { Out-of-plane } \\
\text { deformation }\end{array}$ & U_YY & $0 \sim 3.0 \mathrm{~mm}$ & $0.1 \mathrm{~mm}$ \\
\cline { 2 - 5 } & $\begin{array}{l}\text { Plastic strain } \\
\text { in cooling } \\
\text { channels }\end{array}$ & ST_PL & 0.02 & 0.001 \\
\cline { 2 - 5 } & $\begin{array}{l}\text { Plastic strain } \\
\text { in LFM }\end{array}$ & ST_PL1 & 0.08 & 0.001 \\
\hline $\begin{array}{l}\text { Total volume } \\
(\text { OBJ })\end{array}$ & V_TOT & & $2000 \mathrm{~mm}^{3}$ \\
\hline
\end{tabular}

\section{RESULTS AND DISCUSSIONS}

Fig. 6 gives optimization results of LFM truss reinforced panels under different loading conditions. It can be found that the thermal-mechanical loading may greatly affect the optimal results and truss configurations.

Due to the pressure loads and extreme heat flux, plastic strain may occur in the most highly stressed locations for actively-cooled panels. Although the temperature differences, and hence the thermal stresses, are greatest at the channel inlet, the material strength is also greatest at this location. Typical strength reductions with increasing temperature suggest the possibility of the maximum plastic strain at the outlet, where the temperature is at its maximum. For the core channel shape, the internal fuel pressure may induce large stresses. The external pressure may cause large vertical displacement and stresses.

An assessment of light-weight performance of the optimized actively-cooled panels is made through comparisons of their weights or volumes. The optimal results after second- time-loop optimizations are presented in Table 2. The weight reduction efficiency of LFM truss reinforced actively-cooled panel over non-reinforced one is evident. Weight-reduction rate can be calculated as

$$
\eta=\frac{S J(2)-S J(1)}{S J(1)} \times 100 \%
$$

Values of DVs in the optimal designs are listed in Table 3.

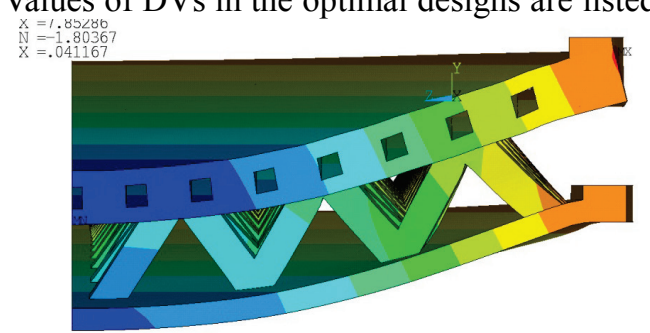

(a) $5 \mathrm{MPa}$ pressure in the combustion side, $1.5 \mathrm{MPa}$ pressure in the cooling channels

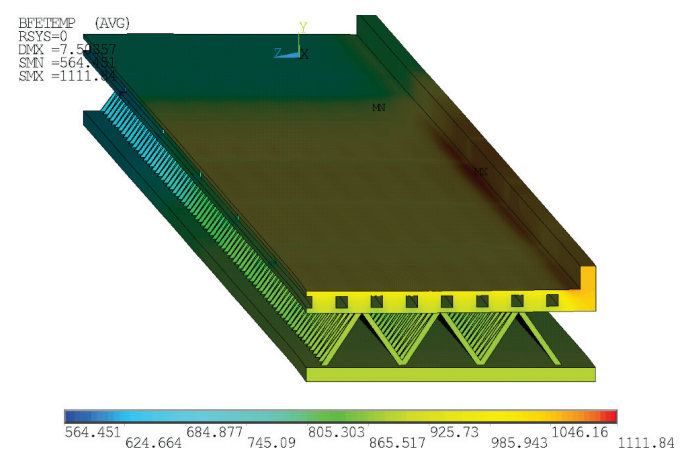

(b) no pressure applied in combustion side and cooling channels Figure. 6: Optimization results of different loading conditions

Table 2: Weight-reduction rate

\begin{tabular}{|c|c|c|c|c|c|}
\hline Structure & \multicolumn{2}{|c|}{$\mathrm{V}\left(\mathrm{mm}^{3}\right)$} & \multicolumn{3}{|c|}{ Weight-reduction rate $\eta$} \\
\hline $\mathrm{SJ}(1)$ & \multicolumn{2}{|c|}{263750} & \multicolumn{3}{|c|}{0} \\
\hline $\mathrm{SJ}(2)$ & \multicolumn{2}{|c|}{213680} & \multicolumn{3}{|c|}{$19.6 \%$} \\
\hline \multicolumn{6}{|c|}{$\begin{array}{l}\text { SJ (1)- non-reinforced panel } \\
\text { SJ (2)- pyramidal LFM truss reinforced panel }\end{array}$} \\
\hline $\begin{array}{c}\text { Optimization } \\
\text { parameters }\end{array}$ & $\begin{array}{l}\text { H_0 } \\
(\mathbf{m m})\end{array}$ & $\begin{array}{c}\text { H_1 } \\
(\mathbf{m m})\end{array}$ & $\begin{array}{c}\text { H_2 } \\
(\mathbf{m m})\end{array}$ & $\begin{array}{c}\mathbf{t} \\
(\mathbf{m m})\end{array}$ & $\begin{array}{c}\mathbf{H} \\
(\mathbf{m m})\end{array}$ \\
\hline SJ1 & 1.39 & 6.49 & & & \\
\hline $\mathrm{SJ} 2$ & 1.09 & 0.92 & 1.01 & 0.97 & 7.40 \\
\hline
\end{tabular}




\section{FABRICATION OF REINFORCED PANELS}

We have also fabricated this type of actively-cooled panel in the laboratory level, as illustrate in Fig.7. The length and width is $800 \mathrm{~mm}$ and $70 \mathrm{~mm}$ respectively, and the panel thickness is $11.5 \mathrm{~mm}$. The relative density for the pyramidal LFM truss is about $3.4 \%$. The whole panel weight is only $1.89 \mathrm{Kg}$. The panel has passed $10 \mathrm{MPa}$ internal pressure test and maintains structural integrity.

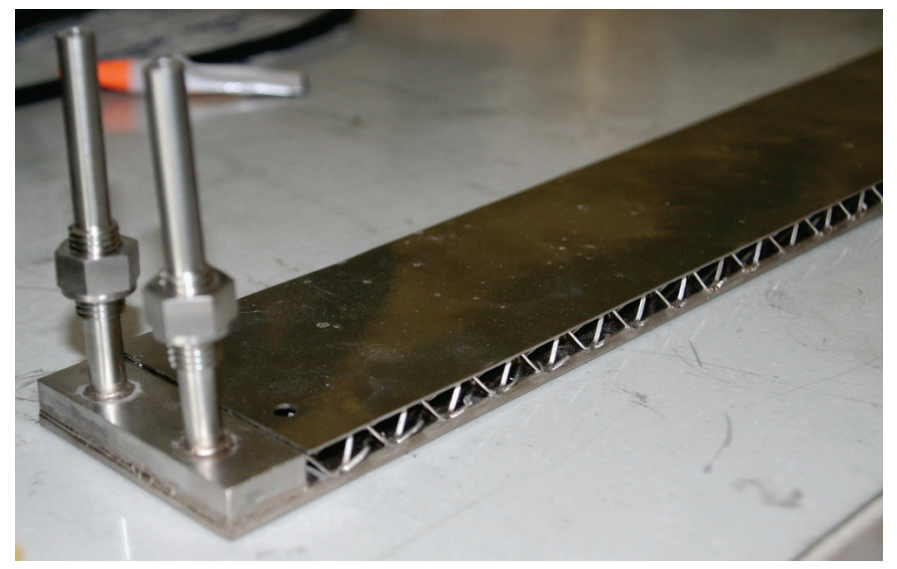

Figure. 7: Fabrication of LFM reinforced actively-cooled panel

\section{CONCLUSIONS}

A thermal-structural analysis and optimization design for lightweight LFM truss reinforced actively-cooled panels has been described and implemented. The results indicate that weight-reduction of the reinforced design is efficient. The comparison of non-reinforced actively-cooled panel with the reinforced panel indicates, after optimization, the weight reduction rate may reach as high as $19.6 \%$, while maintaining the thermal protection capability and load bearing capability. The fabricated LFM truss reinforced actively-cooled panel shows good mechanical behaviors.

\section{ACKNOWLEDGMENTS}

Finical supports from National Natural Science Foundation of China (Grant Nos. 91016025 and 91216303) are gratefully acknowledged. The authors would like to thank Prof. X. J. Fan and Dr. F. Q. Zhong at State Key Laboratory of Hightemperature Gas Dynamics for beneficial discussion on the thermal loadings and thermal analysis.

\section{REFERENCES}

[1] Wagner, W.R. and Shoji, J.M., Advanced Regenerative Cooling Techniques for Future Space Transportation Systems, AIAA-75-1247, 1975.

[2] Powell, O.A., Edwards, J.T., Norries, R.B., Numbers, K.E. and Pearce, J.A., Development of Hydrocarbon-Fueled Scramjet Engines: The Hypersonic Technology(HyTech)
Program, Journal of Propulsion and Power, Vol. 17, No. 6, 2001, pp. 1170-1176.

[3] Lu Y., Li, L. and Fan, X.J. A Thermal Analysis Method for Fuel-Cooled Combustor Structure based on Heat Flux Measurement, AIAA 2012-5878, 2012.

[4] Deshpande, V.S., Fleck, N.A. Collapse of truss core sandwich beams in 3-point bending, International Journal of Solids and Structures, 38, pp. 6275-6305, 2001.

[5] Rathbun, H.J., Zok, F.W., Evans, A.G. Strength optimization of metallic sandwich panels subject to bending, International Journal of Solids and Structures, 42,pp.6643-6661,2005.

[6] Z. Wei, F.W. Zok and A.G. Evans, Design of sandwich panels with prismatic cores, Journal of Engineering Materials and Technology, 128, pp. 186, 2006.

[7] T. Kim, C.Y. Zhao, T.J. Lu and H.P. Hodson, Convective heat dissipation with lattice-frame materials, Mechanics of Materials, 36, pp, 767-780, 2004.

[8] T. J. Lu. Valdevit and A.G. Evans, Actively-cooled by metallic sandwich structures with periodic cores, Progress in Materials Science, 50,pp.789-815,2005

[9] N. Wicks and J.W. Hutchinson, Optimal truss plates, Internal Journal of Solids and Structures, 38, pp.5165-5183, 2001.

[10] T.WANG, S.LI and S.R. Nutt, Optimal design of acoustical sandwich panels with a genetic algorithm, Applied Acoustics, 70, pp, 416-425, 2009.

[11]H.W. Song, C.W. Wu, F.Q. Zhong, Q.H. Sun, X.J. Fan, J. Fan. Effect of aerodynamic heating on thermal-structural behavior of actively cooled supersonic combustor. CSTAM 2011-2781, Sanya, Hainan, China, 2011.(in Chinese) 


\section{ANNEX A}

THERMAL LOADINGS ALONG THE PANEL, WORKING AT MACH $6{ }^{[11]}$
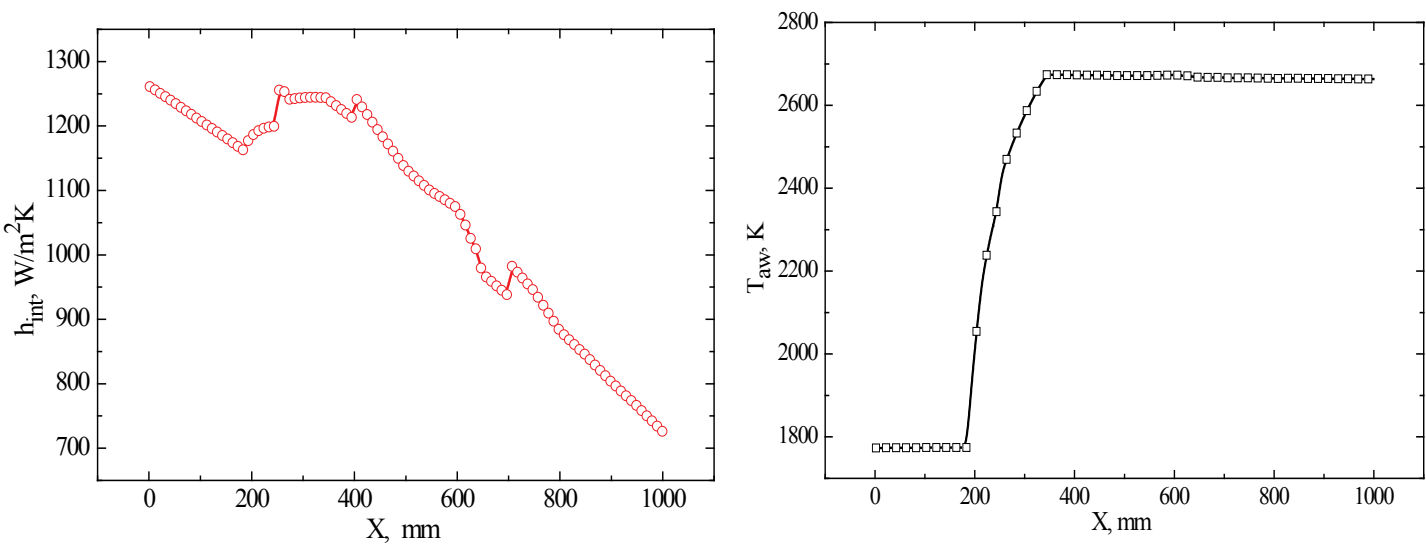

(a) convective coefficient along combustion side

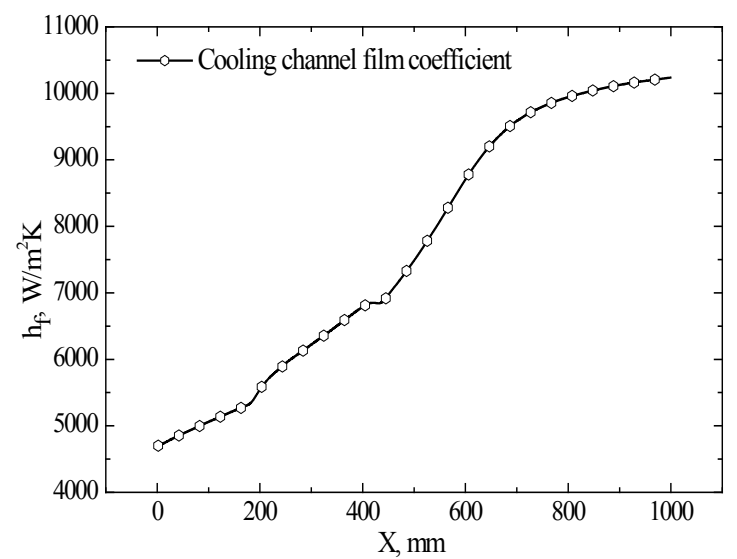

(c) convective coefficient along cooling channels (b) adiabatic temperature along combustion side

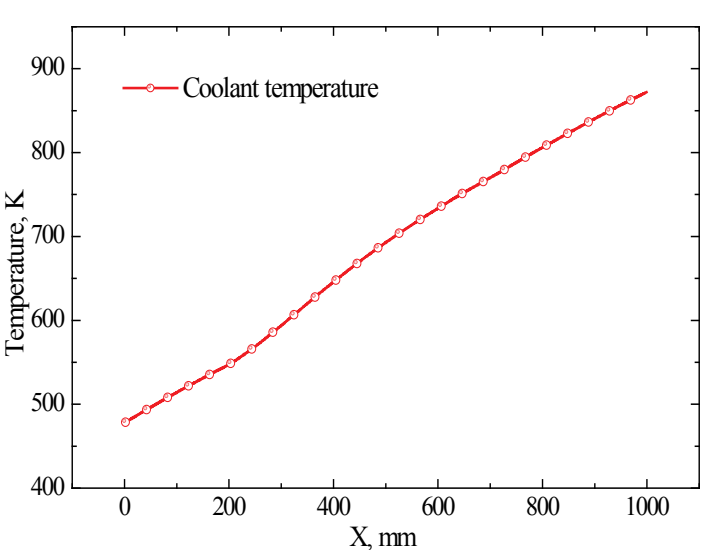

(d) coolant temperature along cooling channels 